\title{
Impairment of Cerebral Blood Flow Autoregulation in the Newborn Lamb by Hypoxia
}

\author{
ARNOLD TWEED, JACQUES COTE, HANS LOU, GEORGE GREGORY, AND JOHN WADE
}

Department of Anaesthesia, University of Manitoba, Winnipeg, Manitoba, Canada

\begin{abstract}
Autoregulation of cerebral blood flow has been demonstrated in both fetal and newborn animal models under normoxic conditions. In the present experiments we have attempted to define the minimal hypoxic insult which impairs autoregulation in the newborn lamb and to assess the time to recovery. We measured cerebral blood flow by the intracarotid ${ }^{133}$ Xe method in fifteen 4 - to 9-day-old lambs and tested autoregulation of cerebral blood flow by increasing blood pressure $20-30 \%$ with phenylephrine. Autoregulation was tested in the control state and at successive time intervals after an hypoxic stress $\left(\mathrm{PaO}_{2}\right.$ of $30 \mathrm{~mm} \mathrm{Hg}$ ) of 10 or $20 \mathrm{~min}$. We found that cerebral autoregulation was abolished after 20 min of hypoxia and recovered within $7 \mathrm{~h}$. Since this model identifies the minimal hypoxic insult to abolish autoregulation it might be used to study means to protect autoregulation or to hasten its recovery after hypoxia. (Pediatr Res 20: 516-519, 1986)
\end{abstract}

\section{Abbreviations}

CBF, cerebral blood flow

MABP, mean arterial blood pressure

IAI, index of autoregulatory impairment

Autoregulation of the cerebral circulation has not yet been demonstrated in healthy human newborns. In sick newborns the $\mathrm{CBF}$ varied directly with the arterial pressure, i.e. autoregulation was impaired (1). To study experimentally the regulation of $\mathrm{CBF}$ under normal and pathologic conditions, several animal models have been used. The newborn lamb, delivered by cesarian section, was found to autoregulate between a mean arterial blood pressure (MABP) of 45 and 90 torr (2). Preterm fetal lambs also autoregulate their $\mathrm{CBF}$, although over a narrower range $(45-80$ $\mathrm{mm} \mathrm{Hg}$ ), and at a resting pressure closer to their lower limit of autoregulation (3). The newborn dog, which has an immature brain at birth, was also observed to autoregulate between an MABP of 27 and 97 torr (4). However, the vulnerability of autoregulation to hypoxia or asphyxia has not been studied in the newborn of any species.

We used newborn lambs to study cerebral autoregulation during normoxia and following hypoxia. Our objectives were to demonstrate autoregulation of $\mathrm{CBF}$ in the normoxic state, and to examine its vulnerability to hypoxia. Both the hypoxic threshold for impairment of autoregulation and the time to recovery have been examined.

Received June 28, 1985; accepted January 30, 1986

Reprints W. A. Tweed, M.D., Department of Anaesthesia, University Hospital, P.O. Box 5339, Station "A", London, Ontario, Canada, N6A 5A5.

Supported by the Medical Research Council of Canada, the Manitoba Heart Foundation, and the Danish Spastic Society.

\section{METHODS}

Animal preparation. We used 15 healthy newborn lambs of both sexes, with a mean age of 5 days (range 4-9) and mean weight of $5.3 \mathrm{~kg}$ (range 4.4-7.0). Anesthesia was induced with inhalation of halothane (2-4\%) in oxygen through a face mask, and an endotracheal tube was passed under direct vision. During the surgical preparation the anesthesia was maintained with halothane $1 \%$ in oxygen and ventilation was controlled. Polyvinyl catheters (ID $0.86 \mathrm{~mm}$ ) were placed in both femoral veins and in one femoral artery. Through an incision at the angle of the maxilla the left lingual artery was cannulated with a catheter whose tip lay at the origin of this artery from the external carotid artery. A burr hole of $1 \mathrm{~cm}$ was made over the parietal lobe. At the end of the surgery all wounds were infiltrated with lidocaine, halothane was discontinued, and the lambs were ventilated with a mixture of nitrous oxide $70 \%$ and oxygen $30 \%$. During the whole experimental period each animal received an infusion of dextrose $10 \%$ in sodium chloride $0.9 \%$ at the rate of $6 \mathrm{ml} / \mathrm{kg} / \mathrm{h}$.

Muscle relaxation was maintained by an initial dose of $2 \mathrm{mg}$ of pancuronium bromide and then $0.25 \mathrm{mg}$ each hour, and rectal temperature was maintained between 38 and $39^{\circ} \mathrm{C}$ with an electric mattress. Arterial blood $\mathrm{PO}_{2}, \mathrm{PCO}_{2}$, and $\mathrm{pH}$ were measured on a Corning pH/Blood Gas apparatus (Corning Medica, Medfield, MA) and temperature corrected; percent hemoglobin $\mathrm{O}_{2}$ saturation was measured with a microoximeter (OSM-2 Hemoximeter, Radiometer, Copenhagen, Denmark) and $\mathrm{O}_{2}$ contents calculated. MABP was monitored continuously via the femoral artery catheter using a Statham P23 transducer connected to a multichannel recorder. The arterial $\mathrm{PO}_{2}$ was controlled by adjusting the concentration of $\mathrm{FiO}_{2}$.

$C B F$ measurements. $\mathrm{CBF}$ was measured by recording the clearance curve of ${ }^{133} \mathrm{Xe}$ injected into the carotid artery through the lingual artery catheter. This method has been well described (5). In brief we injected $0.5 \mathrm{mCi}$ of ${ }^{133} \mathrm{Xe}$ in a volume of $1 \mathrm{ml}$ over 3-5 s. This volume and rate of injection do not affect the pressure in the carotid artery (2). Decay of the intracerebral activity was measured with a lead collimated thallium-activated $\mathrm{NaI}$ detector of $5 \mathrm{~mm}$ in diameter. To decrease extracerebral contamination the detector was placed directly over the dura through a burr hole. The counter was connected to a ratemeter (Medimatic, Irvine, CA) with a variable time constant and an $\mathrm{X}-\mathrm{Y}$ recorder. A time constant of $2 \mathrm{~s}$ was used for the time of the injection and $5 \mathrm{~s}$ for the remaining $2 \mathrm{~min}$. The clearance curve was plotted on semilog paper, and the value of CBF was derived from the initial part of the clearance curve (5), the portion of the curve between 15 and $75 \mathrm{~s}$ after the peak count rate.

Autoregulation tests. Autoregulation was tested by three measurements of CBF: 1) resting blood pressure; 2) $15 \mathrm{~min}$ after increasing blood pressure $20-30 \%$ over the resting level by an infusion of $0.025 \%$ phenylephrine; and 3) $15 \mathrm{~min}$ after blood pressure had returned to normal.

We compared autoregulation at different times after hypoxia 
with that observed during the normoxic control state. A quantitative IAI was defined as percent change in $\mathrm{CBF}$ divided by percent change in MABP $(\triangle \mathrm{CBF} \% / \triangle \mathrm{MABP} \%)$. Thus an IAI of zero indicates perfect autoregulation, values of $0-1$ indicate progressive impairment, and values of one or over indicate pressure passive $\mathrm{CBF}$. A decrease in $\mathrm{CBF}$ with increased MABP results in a negative value for IAI and is interpreted as intact autoregulation.

After completion of surgery, mechanical ventilation was adjusted to maintain $\mathrm{PCO}_{2}$ at $34 \pm 2$ torr, the normal level for the newborn lamb. Autoregulation was tested when blood gases and MABP were stable. After a control study demonstrating intact autoregulation, hypoxia was produced by a decrease of $\mathrm{FIO}_{2}$ to $0.15-0.10 . \mathrm{PaO}_{2}$ was measured repeatedly and maintained near 30 torr for 10 or $20 \mathrm{~min}$, then returned to control values by restoring $\mathrm{FlO}_{2}$. $\mathrm{CBF}$ was measured once during the midpoint of hypoxia in seven animals of the 20 -min group. Fifteen-30 min after the hypoxic insult autoregulation was again tested as described above $\left(\mathrm{R}_{0}\right)$.

Three animals with intact autoregulation after $10 \mathrm{~min}$ of hypoxia were studied a second time. We waited $1-2 \mathrm{~h}$, then induced a second hypoxic insult for a period of $20 \mathrm{~min}$. These three animals therefore are included in both the 10- and 20-min groups.

In all animals with autoregulatory impairment after $20 \mathrm{~min}$ of hypoxia autoregulation tests were repeated at approximately two hourly intervals while control state experimental conditions were maintained. Ten animals were tested between $2-4 \mathrm{~h}$ after hypoxia $\left(R_{1}\right)$, but due to time constraints only five experiments could be continued longer. These five animals were again tested between 5-7 h after hypoxia $\left(\mathrm{R}_{2}\right)$.

The animals were then killed by an intravenous injection of $\mathrm{KCl}$, and the position of each catheter was checked. The skull was opened, and the dura and brain were also carefully inspected at the burr hole site for contusion or bleeding.

Statistical analyses of autoregulation tests were performed by one-way ANOVA comparing CBF values before, during, and after hypertension. Values for IAI were compared by ANOVA for nonrepeated measures with the least significant difference test for intergroup comparisons.

\section{RESULTS}

Autoregulation was impaired in five of the 15 animals immediately after surgery (IAI $=1.45 \pm 0.76$ ). They were retested repeatedly and had recovered complete autoregulation between $5-9 \mathrm{~h}(\mathrm{IAI}=0.06 \pm 0.21)$. The other 10 animals autoregulated on first measurement, within $2 \mathrm{~h}$ after surgery. Some animals in both groups had a mild transient metabolic acidosis after surgery, but there were no significant differences in arterial blood gases, anesthesia, or surgical preparation between those who did or did not immediately autoregulate.

Arterial blood gases and circulatory measurements throughout the periods of hypoxia are shown in Table $1 . \mathrm{PaO}_{2}$ was decreased to about $30 \mathrm{~mm} \mathrm{Hg}$ in both groups. The cardiovascular responses to hypoxia were variable, with the only statistically significant change being an increase in heart rate in the 20-min group. Arterial oxygen content was determined in the 20 -min group and decreased significantly to $50 \%$ of normal.

Seven animals were exposed to $10 \mathrm{~min}$ of hypoxia. Mean CBF was unchanged during induced hypertension after the 10-min insult $\left(R_{0} 10\right)$ but one of the seven had pressure passive $C B F$, i.e. impaired autoregulation, thus the large SD (Table 2) for this group.

Hypoxia of 20 min duration was produced in 11 animals. Mean CBF increased significantly with an induced hypertension $1 / 4-1 / 2 \mathrm{~h}$ after the 20 -min insult $\left(\mathrm{R}_{0} 20\right)$, with an IAI of 1.08 , suggesting completely pressure passive CBF (Table 2). Only one animal did not have pressure dependent CBF after $20 \mathrm{~min}$ hypoxia. By $2-4 \mathrm{~h}\left(\mathrm{R}_{1} 20\right)$ autoregulation had partially recovered, and by $5-7\left(R_{2} 20\right)$ it had completely recovered.

In seven animals $C B F$ was also measured during the period of hypoxia and a consistent and significant increase of $75-100 \%$ was observed.

Table 1. Physiologic data before, during, and after 10 or 20 min of hypoxia (Mean $\pm S D)^{*}$

\begin{tabular}{|c|c|c|c|c|c|c|}
\hline & \multicolumn{3}{|c|}{ 10-Min hypoxia group } & \multicolumn{3}{|c|}{ 20-Min hypoxia group } \\
\hline & Before $(\mathrm{C})$ & During & After (Ro) & Before $(\mathrm{C})$ & During & After (Ro) \\
\hline $\mathrm{pH}$ & $7.37 \pm 0.03$ & $7.39 \pm 0.03$ & $7.38 \pm 0.03$ & $7.37 \pm 0.08$ & $7.37 \pm 0.08$ & $7.34 \pm 0.08$ \\
\hline $\mathrm{PO}_{2}$ & $86 \pm 12$ & $31 \pm 1 \dagger$ & $84 \pm 9$ & $84 \pm 19$ & $30 \pm 2 \dagger$ & $82 \pm 14$ \\
\hline $\mathrm{PCO}_{2}$ & $34 \pm 3$ & $36 \pm 3$ & $35 \pm 3$ & $33 \pm 2$ & $33 \pm 2$ & $34 \pm 2$ \\
\hline $\mathrm{CaO}_{2}$ & & & & $11.8 \pm 0.6$ & $6.1 \pm 1.5 \dagger$ & $13 \pm 2.5$ \\
\hline $\mathrm{HR}$ & $216 \pm 23$ & $226 \pm 21$ & $221 \pm 17$ & $219 \pm 24$ & $253 \pm 39 \dagger$ & $235 \pm 22$ \\
\hline MABP & $77 \pm 7$ & $78 \pm 7$ & $79 \pm 6$ & $84 \pm 9$ & $78 \pm 4$ & $78 \pm 4$ \\
\hline
\end{tabular}

* $\mathrm{CaO}_{2}$, calculated arterial oxygen content; $\mathrm{HR}$, heart rate.

$\dagger p<0.05$.

\begin{tabular}{|c|c|c|c|c|c|c|c|c|c|c|c|}
\hline & \multicolumn{4}{|c|}{ MABP } & \multicolumn{3}{|c|}{$\mathrm{PaCO}_{2}$} & \multicolumn{3}{|c|}{$\mathrm{CBF}(\mathrm{ml} / 100 \mathrm{~g} / \mathrm{min})$} & \multirow[b]{2}{*}{ IAI } \\
\hline & $\mathrm{n}$ & 1 & 2 & 3 & 1 & 2 & 3 & 1 & 2 & 3 & \\
\hline $\mathrm{C} 10$ & 7 & $80 \pm 5$ & $100 \pm 7$ & $83 \pm 6$ & $34 \pm 2$ & $33 \pm 2$ & $34 \pm 3$ & $55 \pm 15$ & $54 \pm 17$ & $55 \pm 17$ & $-0.15 \pm 0.4$ \\
\hline $\mathrm{R}_{0} 10$ & 7 & $77 \pm 4$ & $98 \pm 7$ & $81 \pm 6$ & $34 \pm 3$ & $34 \pm 2$ & $34 \pm 2$ & $48 \pm 10$ & $49 \pm 14$ & $46 \pm 12$ & $0.22 \pm 1.04$ \\
\hline $\mathrm{C} 20$ & 11 & $79 \pm 7$ & $104 \pm 7$ & $83 \pm 10$ & $34 \pm 3$ & $34 \pm 3$ & $33 \pm 2$ & $82 \pm 31$ & $83 \pm 33$ & $81 \pm 29$ & $0.06 \pm 0.19$ \\
\hline $\mathrm{R}_{0} 20$ & 11 & $80 \pm 8$ & $105 \pm 8$ & $81 \pm 8$ & $33 \pm 2$ & $33 \pm 2$ & $32 \pm 3$ & $73 \pm 28$ & $95 \pm 33^{*}$ & $65 \pm 24$ & $1.08 \pm 0.57$ \\
\hline $\mathrm{R}_{1} 20$ & 10 & $77 \pm 4$ & $102 \pm 5$ & $80 \pm 2$ & $32 \pm 3$ & $32 \pm 3$ & $32 \pm 3$ & $63 \pm 16$ & $81 \pm 34$ & $67 \pm 22$ & $0.76 \pm 0.88$ \\
\hline $\mathrm{R}_{2} 20$ & 5 & $78 \pm 14$ & $102 \pm 18$ & $77 \pm 9$ & $30 \pm 1$ & $29 \pm 2$ & $31 \pm 2$ & $72 \pm 15$ & $73 \pm 9$ & $70 \pm 15$ & $0.15 \pm 0.46$ \\
\hline
\end{tabular}

* Each test of autoregulation consisted of three measurements of CBF: at normotension (1), induced hypertension (2), and repeat normotension (3). $\mathrm{C} 10$ and $\mathrm{C} 20$ are the control periods for the 10 - and 20-min hypoxia groups. Autoregulation was then tested at three different intervals during recovery from hypoxia: $0-0.5 \mathrm{~h}\left(\mathrm{R}_{0}\right), 2-4 \mathrm{~h}\left(\mathrm{R}_{1}\right)$, and $5-7 \mathrm{~h}\left(\mathrm{R}_{2}\right)$. CBF changes during autoregulation tests were analyzed statistically by one-way analysis of variance. A significant change in $\operatorname{CBF}(p<0.01)$ occurred at $\mathrm{R}_{0} 20$. All values are mean $\pm \mathrm{SD}$.

$\dagger p<0.01$ 
Table 3. Quantitation of impaired autoregulation before and after 10 and $20 \mathrm{~min}$ of hypoxia*

\begin{tabular}{ccccccc}
\hline $\begin{array}{c}\text { Conditions compared: } \\
\text { (a to b) }\end{array}$ & \multicolumn{2}{c}{ Mean IAI* } & & & & \\
\cline { 2 - 6 } & (a) & (b) & $\Delta$ & $t$ & $\mathrm{dF}$ & $p$ \\
\hline$\left(\mathrm{R}_{0}\right.$ to $\left.\mathrm{C}\right) 10$ & 0.22 & -0.15 & -0.37 & 0.97 & 12 & $\mathrm{NS}$ \\
$\left(\mathrm{R}_{0}\right.$ to $\left.\mathrm{C}\right) 20$ & 1.08 & 0.06 & 1.02 & 5.7 & 20 & $<0.001$ \\
$\left(\mathrm{R}_{1}\right.$ to $\left.\mathrm{C}\right) 20$ & 0.76 & 0.06 & 0.7 & 2.59 & 19 & $<0.02$ \\
$\left(\mathrm{R}_{2}\right.$ to $\left.\mathrm{C}\right) 20$ & 0.15 & 0.06 & 0.09 & 0.58 & 14 & $\mathrm{NS}$ \\
$\left(\mathrm{R}_{1}\right.$ to $\left.\mathrm{R}_{0}\right) 20$ & 0.76 & 1.08 & -0.32 & 0.98 & 19 & $\mathrm{NS}$ \\
$\left(\mathrm{R}_{2}\right.$ to $\left.\mathrm{R}_{0}\right) 20$ & 0.15 & 1.08 & -0.93 & -3.17 & 14 & $<0.01$ \\
\hline
\end{tabular}

* IAI is calculated as percent change in CBF divided by percent change in MABP. The IAI was calculated for the control state in the two hypoxia groups $(\mathrm{C} 10$ and $\mathrm{C} 20)$ and for three different times during recovery from hypoxia: $0-0.5 \mathrm{~h}\left(\mathrm{R}_{0}\right), 2-4 \mathrm{~h}\left(\mathrm{R}_{1}\right)$, and 5-7 h $\left(\mathrm{R}_{2}\right)$. Recovery $\left(\mathrm{R}_{0}\right)$ and control $(\mathrm{C} 10)$ values in the $10-\mathrm{min}$ group were compared by paired $t$ test. Changes in IAI induced by $20 \mathrm{~min}$ of hypoxia were highly significant by ANOVA $(p<0.001)$, and multiple intergroup comparisons by the test of least significant differences showed significant changes from control at $R_{0}$ and $R_{1}$, but not at $R_{2}$.

Autoregulatory impairment was quantitated by calculation of an IAI as percent change in CBF divided by percent change in MABP ( $\triangle \mathrm{CBF} \% / \triangle \mathrm{MABP} \%)$ (Table 3 ). In Table 3 IAI at the three different times during recovery from hypoxia and control IAI are compared. Note that autoregulation was not impaired by 10 min of hypoxia, but was completely abolished after $20 \mathrm{~min}$, and changes in the 20 -min group are highly significant when examined by ANOVA $(p<0.001)$. When compared to control differences were still significant at 2-4 h, but not at 5-7 h.

\section{DISCUSSION}

We have demonstrated that autoregulation of the cerebral circulation is impaired after $20 \mathrm{~min}$ of moderately severe hypoxia $\left(\mathrm{PaO}_{2}=30 \mathrm{~mm} \mathrm{Hg}\right)$ in the newborn lamb, with recovery within $7 \mathrm{~h}$. Shorter periods of hypoxia, at the same arterial oxygen tension, did not disturb the ability to autoregulate CBF.

The increase of CBF during hypoxia is well documented (6). In adult rats, with severe hypoxia, an increase of up to $500 \%$ is reported (7). Also the lack of modification of MABP and heart rate does not indicate there is no circulatory adjustment to hypoxia; the major adjustment is a redistribution of blood flow to vital organs (8). In these studies $\mathrm{CBF}$ was measured during the 20 -min period of hypoxia in seven animals and invariably found to be $75-100 \%$ increased. Since CBF was measured at the midpoint of hypoxia this would correspond approximately to the 10 -min insult. Therefore $10 \mathrm{~min}$ of hypoxia was sufficient to induce cerebral hypoxic vasodilatation, but not sufficient to subsequently impair autoregulation of $\mathrm{CBF}$.

Since we did not test autoregulation during hypoxia we cannot say whether impairment is immediate at a critical threshold (i.e. an all or none phenomenon) or is initiated at a critical threshold and progresses over time (i.e. a graded phenomenon). These studies support the latter view, with impairment behaving as a graded phenomenon but initiated at a critical threshold of hypoxia.

Since we did not measure either hydrogen ion or potassium ion concentrations in the cortical interstitial fluid, we do not know if 10 or 20 min of hypoxia at these levels induced tissue acidosis or energy depletion. It remains, therefore, to measure the changes in metabolism and composition of extracellular fluid that determine the critical threshold for impairment of autoregulation. Probably the degree of hypoxia is also a determinant factor. $\mathrm{A} \mathrm{PaO}$ of 30 was chosen because it was the lowest $\mathrm{PO}_{2}$ that our experimental model would tolerate for $20 \mathrm{~min}$ and maintain stability of systemic blood pressure, circulation, and blood acid base. At a $\mathrm{PO}_{2}$ of $30 \mathrm{~mm} \mathrm{Hg}$ we measured hemoglobin
$\mathrm{O}_{2}$ saturation of about $50 \%$, values similar to those previously reported for the 1-wk-old lamb (9).

We should also mention the possible additive effects of two episodes of hypoxia since three animals were subjected to both 10- and 20-min hypoxic insults. If autoregulation was intact after the 10 -min insult we waited $1-2 \mathrm{~h}$ before subjecting the animal to a 20-min insult. Before inducing the second hypoxia we confirmed again that autoregulation was intact and that CBF had returned to control values. We cannot, however, completely dismiss the possibility that a mild residual metabolic disturbance of brain tissue may have been additive to the second hypoxia. However, the animals subjected to only a 20 -min hypoxic episode did not differ from those subjected to two episodes.

Impaired autoregulation immediately after surgery was found in five animals. During the anesthetic induction we attempted to avoid hypoxia, hypotension, and hypertension by quickly inducing anesthesia with halothane in oxygen, then rapidly intubating the trachea and controlling ventilation. However, a mild metabolic acidosis immediately after surgery was evident in some animals in both the autoregulating and nonautoregulating groups. This recovered spontaneously in 1-2 h, or after a small amount of intravenous sodium bicarbonate. The effect of the surgical preparation was recognized early in the study, consequently we always waited until autoregulation was recovered and stable before proceeding with the experiment. However, we cannot rule out an additive effect of the surgical stress to the subsequent hypoxia. Anesthetic effects are less likely since neither halothane (10) nor nitrous oxide (11) impairs autoregulation if hypotension is avoided. Nitrous oxide has minimal effects on $\mathrm{CBF}$ and blocks the severe stress effect seen in unanesthetized animals (11). However, this observation emphasizes the importance of carefully defining the control state in experiments such as these.

Autoregulation of $\mathrm{CBF}$ has been observed in the young of two species: preterm (3) and full term fetal lambs (12), newborn lambs (2), and the newborn puppy (4). The vulnerability of autoregulation to various insults has also been demonstrated in both adult humans (6) and adult animals $(13,14)$. Recently we have shown that in the fetal lamb autoregulation is dependent on arterial oxygen and is consistently impaired when arterial oxygen saturation in utero is less than $50 \%$ (12). This is the same level of saturation achieved in these experiments with a $\mathrm{PaO}_{2}$ of 30 in 4 - to 9 -day-old lambs.

There are few studies that examine the time course to recovery of autoregulation and none demonstrating recovery after an hypoxic insult. Reported studies of recovery deal mainly with the effects of drugs (15) and are therefore not useful for comparison.

The absence of autoregulation in the cerebral circulation is now considered to be one of the important predisposing factors leading to cerebral infarction of the asphyxiated human baby $(16,17)$. However, before we attempt to transpose these results to humans it is worthwhile underlining several points. The brain of the newborn lamb is more mature than that of the human. In addition a pure hypoxia is unlikely to occur as an isolated event in the clinical context; acidosis and hypotension often accompany hypoxia. Finally, little is known about cerebral autoregulation in the human baby, although in sick newborn infants autoregulation has been shown to be impaired (1). If the cerebral vasculature of the human baby is similar to that of animal models, we can expect a recovery of autoregulation within a few hours of restoring a normal milieu. Therefore there appears to be a reasonable rationale to investigate measures to preserve or restore autoregulation.

In conclusion we have established that cerebral autoregulation is present in the newborn lamb, and this mechanism is reversibly abolished by hypoxia. Although CBF doubled after $10 \mathrm{~min}$ of hypoxia, this was not a sufficient insult to abolish autoregulation. However, a 20 -min period of hypoxia reversibly disturbed this 
mechanism, with recovery observed within $7 \mathrm{~h}$. If we also count the five animals with impaired autoregulation after surgical preparation, we have demonstrated recovery within $9 \mathrm{~h}$ on a total of 10 occasions, while in the remainder the experiments were terminated within $5 \mathrm{~h}$ after hypoxia and before recovery was observed. Therefore we believe that this is a suitable model to study therapeutic interventions to protect autoregulation during and after hypoxia.

Acknowledgments. The authors thank Mr. Wayne Pucci and Miss Maureen Cumming for technical help.

\section{REFERENCES}

1. Lou HC, Lassen NA, Friis-Hansen B 1979 Impaired autoregulation of cerebral blood flow in the distressed newborn infant. $J$ Pediatr 94:118-12

2. Purves MJ, James IM 1969 Observations on the control of cerebral blood flow in the sheep fetus and newborn lamb. Circ Res 25:651-667

3. Papile LA, Rudolph AM, Heymann MA 1985 Autoregulation of cerebral blood flow in the preterm fetal lamb. Pediatr Res 19:159-161

4. Hernandez MJ, Brennan RW, Bowman GS 1980 Autoregulation of cerebral blood flow in the newborn dog. Brain Res 185:199-202

5. Olesen V, Paulson OB, Lassen NA 1971 Regional cerebral blood flow in man determined by the initial slope of the clearance of intra-arterially injected ${ }^{133}$ Xe. Stroke 2:519-540

6. Lassen NA 1974 Control of cerebral circulation in health and disease. Circ Res
$34: 749-760$

7. Johannson H, Siesjo BK 1975 Cerebral blood flow and oxygen consumption in the rat in hypoxic hypoxia. Acta Physiol Scand 93:269-276

8. Heistad DD, Abboud FM 1980 Circulatory adjustments to hypoxia. Circulation 61:463-470

9. Lister G, Walter TK, Versmold HJ, Dallman RR, Rudolph AM 1979 Oxygen delivery in lambs: cardiovascular and hematologic development. Am J Physiol 237:H668-H675

10. Kearney NP, Pickerodt JW, McDowall DG, Coroneos NJ, Turner JM, Shah ZP 1973 Cerebral circulatory and metabolic effects of hypotension produced by deep halothane anaesthesia. J Neurol Neurosurg Psychol 36:898-905

11. Ingvar M, Abdul-Rahman A, Siesjo BK 1980 Local cerebral glucose consumption in the artificially ventilated rat: influence of nitrous oxide analgesia and phenobarbital anesthesia. Acta Physiol Scand 109:177-185

12. Tweed WA, Cote J, Pash M, Lou H 1983 Arterial oxygenation determines autoregulation of cerebral blood flow in the fetal lamb. Pediatr Res 17:246249

13. Freeman J, Ingvar DH 1968 Elimination by hypoxia of cerebral blood flow autoregulation and EEG relationship. Exp Brain Res 5:61-71

14. Haggendal E, Johansson B 1965 Effects of arterial carbon dioxide tension and oxygen saturation on CBF autoregulation in dogs. Acta Physiol Scand 66(suppl 258):27-53

15. Kearney NP, McDowall DG, Turner JM, Lane JR, Omuda YO 1973 The effects of profound hypotension induced with sodium nitroprusside on cerebral blood flow and metabolism in the baboon. Br J Anaesth 45:639

16. Friis-Hansen B 1985 Perinatal brain injury and cerebral blood flow in newborn infants. Acta Paediatr Scand 74:323-331

17. Lou HC 1980 Perinatal hypoxic-ischemic brain damage and intraventricular hemorrhage. A pathogenetic model. Arch Neurol 37:585-587 